\title{
Concurrent Training and Detraining: Brief Review on the Effect of Exercise Intensities
}

\author{
Authors \\ António C. Sousa ${ }^{1,2}$, Henrique Pereira Neiva ${ }^{2,3}$, Mikel Izquierdo4, Eduardo Lusa Cadore ${ }^{5}$, Ana R. Alves ${ }^{6}$, \\ Daniel Almeida Marinho', 2
}

\section{Affiliations}

1 Sport Sciences, University of Beira Interior, Faculty of Social and Human Sciences, Covilha, Portugal

2 Research Center in Sports Sciences Health and Human Development, UBI-CIDESD, Covilhã, Portugal

3 Department of Sport Sciences, University of Beira Interior, CIDESD, Covilhã, Portugal

4 Navarrabiomed, Complejo Hospitalario de Navarra (CHN)-Universidad Pública de Navarra (UPNA), IDISNA, Pamplona, Navarra, Spain and CIBER of Frailty and Healthy Aging (CIBERFES), Instituto de Salud Carlos III, Madrid, Spain

5 Physical Education Scholl, Federal University of Rio Grande do Sul, Porto Alegre, Brazil

6 Department of Education and Social and Behavioral Sciences, Education, Polytechnic Institute of Beja, Beja, Portugal

\section{Key words}

combined endurance and strength training, training intensity, training effect, exercise physiology, strength and aerobic gains, exercise cessation

accepted $\quad 07.07 .2019$

\section{Bibliography}

DOI https://doi.org/10.1055/a-0975-9471

Published online: 2.9.2019

Int J Sports Med 2019; 40: 747-755

(C) Georg Thieme Verlag KG Stuttgart · New York

ISSN 0172-4622

\author{
Correspondence \\ Dr. Daniel Almeida Marinho \\ Sport Sciences, UBI \\ Rua Marquês d'Ávila e Bolama \\ 6201-001 Covilhã \\ Portugal \\ Tel.: + 351275319700, Fax : 00351275320695 \\ marinho.d@gmail.com
}

\section{ABSTRACT}

Concurrent resistance and aerobic training (CT) has been applied to optimize both strength and aerobic performance. However, it should be carefully prescribed, as there are some factors, as the training intensity, which have strong influence on training adaptations. Thus, we conducted a systematic review to analyze the scientific evidence regarding aerobic and resistance exercise intensities during $\mathrm{CT}$ and their effect on performance outcomes. The effects of exercise intensity on a subsequent detraining period were also assessed. Nine studies met the inclusion criteria, the risk of bias was assessed, and the percentage of changes and effect sizes were quantified. CT improved running times $(10 \mathrm{~m}, 30 \mathrm{~m}$ and $10 \mathrm{~km})$ and strength performance (one-repetition maximum, countermovement jump) regardless of exercise intensity used (4-47\%, ES $=0.4-$ 2.8). Nevertheless, higher aerobic training intensities ( $\geq$ lactate threshold intensity) resulted in higher aerobic gains (5$10 \%, E S=0.3-0.6)$, and greater neuromuscular adaptations were found when higher resistance loads ( $\geq 70 \%$ of maximal strength) were used $(10-14 \%$, ES $=0.4-1.3)$. Most traininginduced gains were reversed after $2-4$ weeks of detraining. Although further research is needed, it seems that higher intensities of aerobic or resistance training induce greater aerobic or neuromuscular gains, respectively. Nevertheless, it seems that higher resistance training loads should be combined with lower aerobic training intensities for increased strength gains and minimal losses after detraining.

\section{Introduction}

Concurrent training (CT), which involves a combination of resistance and aerobic regimens, has attracted strong attention from the scientific community in recent years due to its potential to simultaneously induce aerobic and strength gains [1,2]. While some researchers have shown that $\mathrm{CT}$ affects the development of muscle strength and power (i. e., interference effect) [3-7], others have indicated that CT has no inhibitory effect on strength and aerobic development compared to strength training alone [8-15]. The interference between strength and aerobic training can be explained by the training pro- 
gram configuration, such as the volume, intensity, and training frequency [16-18] or even physical fitness level and age [19,20].

The management of both resistance and aerobic exercise variables can maximize performance but also expose athletes to overreaching or overtraining if they are incorrectly manipulated [21]. Varying modalities, intensities, frequencies and volumes of training have been shown to affect the magnitude of molecular signaling and protein synthesis [22,23], which will therefore influence the degree of interference between exercise modes. Thus, the degree of the interference effect can vary depending on depending on how the training variables are configured $[21,23]$. Several studies have indicated that an interference effect exists between aerobic training and resistance training when the weekly training volume is high [21, 24-28]. It seems quite clear that high volumes of aerobic training, either due to an increase in the frequency and/or duration of aerobic exercises, results in the inhibition of strength gains, in contrast to low volumes of aerobic training [27, 28]. According to these studies $[27,28]$, it seems that an increase in the volume of aerobic training induces a higher degree of fatigue, which compromises the quality of strength training and, consequently, the possible chronic adaptations. Nevertheless, it is still not clear what happens on both cardiorespiratory and neuromuscular performance when the intensities of the aerobic or/and strength training performances are manipulated.

Researchers focused on CT have recently tried to understand its effects by studying the detraining period after a CT program $[1,29,30]$. In fact, interruptions in the training process due to illness, post-season vacation, or other factors are ordinary in most of sports [26,31]. The magnitude of this reduction may depend on the duration of the detraining period and on the training level of the subject. It seems that the longer training period, the longer the detraining period needed for severe performance decrements $[1,32]$. Knowing the effects of training on subsequent detraining period will allow to better understand how to design a training program, either to optimize and reduce performance losses, or to better understand how to combine the periodization models regarding the training load and recovery phases to maximize gains and competitive performance [33].

In recent years, several reviews have been published analyzing CT $[21,27,28,34]$, but, to the best of authors' knowledge, no systematic review has comprehensively examined the literature regarding the effects different resistance and/or aerobic intensities in CT and the effects of the subsequent detraining period on performance. Analyzing studies that have evaluated CT intensities would provide coaches and sports scientists with valuable knowledge and strategies to effectively combine aerobic exercise with bouts of resistance training when seeking improved performance across training and competition. Therefore, the current review aims to analyze and compare the effect of training intensity during resistance and aerobic training in CT programs on changes in strength and endurance variables. A secondary purpose was to analyze the effect of training intensity during $\mathrm{CT}$ on the detraining period.

\section{Materials and Methods}

\section{Search strategy}

A systematic review was conducted according to PRISMA (Preferred Reporting Items for Systematic reviews and Meta-analyses) guidelines [35]. A disciplined literature search was independently conducted by two researchers using the Web of Science, PubMed, ScienceDirect, Scholar Google, and Scopus databases. An extensive literature search was conducted from January 1, 1980, to April 30, 2019 , to identify studies related to concurrent training with different aerobic or/and resistance training intensities, and the effects of detraining period in young adults. The search was performed using the Boolean search method, which limited the search results (including AND/OR) to only those documents containing key terms relevant to the scope of this review. The search terms used were “concurrent training”, "resistance training”, "aerobic training”, “detraining", "intensities", and "young adults". The review was conducted in accordance to the International Journal of Sports Medicine ethical standards in sport and exercise science research [36].

\section{Eligibility criteria}

The included studies focused on experimental interventions related to CT and detraining in young adults (between 18 and 35 years old) with performance-related outcomes (i. e. time, velocity, strength, aerobic capacity and power). Studies written in English that were published in a peer-reviewed journal, assessing different intensities of resistance and/or aerobic training during CT programs, and studies on the effect of training intensity during CT on the detraining period, in healthy young adults were included. Review articles (qualitative review, systematic review, and meta-analysis), thesis, dissertations, conference abstracts and proceedings were not considered. Regarding the research question, studies were categorized into the following two main groups: i) effects of concurrent training and ii) effects of detraining. The information extracted from the selected studies was based on research design, aim, subjects, procedures and findings.

\section{Study selection}

The initial search identified 2580 initial studies. After removing duplicates and studies with different types of intervention (e. g., different than longitudinal studies), subjects with other chronological ages (children, elderly), and subjects who did not include a session of CT in the protocol, 2498 studies were excluded. From the remaining studies, the full texts of 13 original research articles were assessed for eligibility, and those that did not meet the inclusion criteria were excluded (e. g., inconclusive information on study procedures). For the qualitative analysis, a total of 9 studies were considered relevant for a detailed analysis. The earliest of these studies was published in 2007 [37], and the most recently published study was from 2019 [30]. The articles were grouped according to the CT intervention ( $n=8)$ or to the presence of detraining $(n=3)$. A detailed flow chart describing the process of selecting the relevant studies is shown in $>$ Fig. 1. 


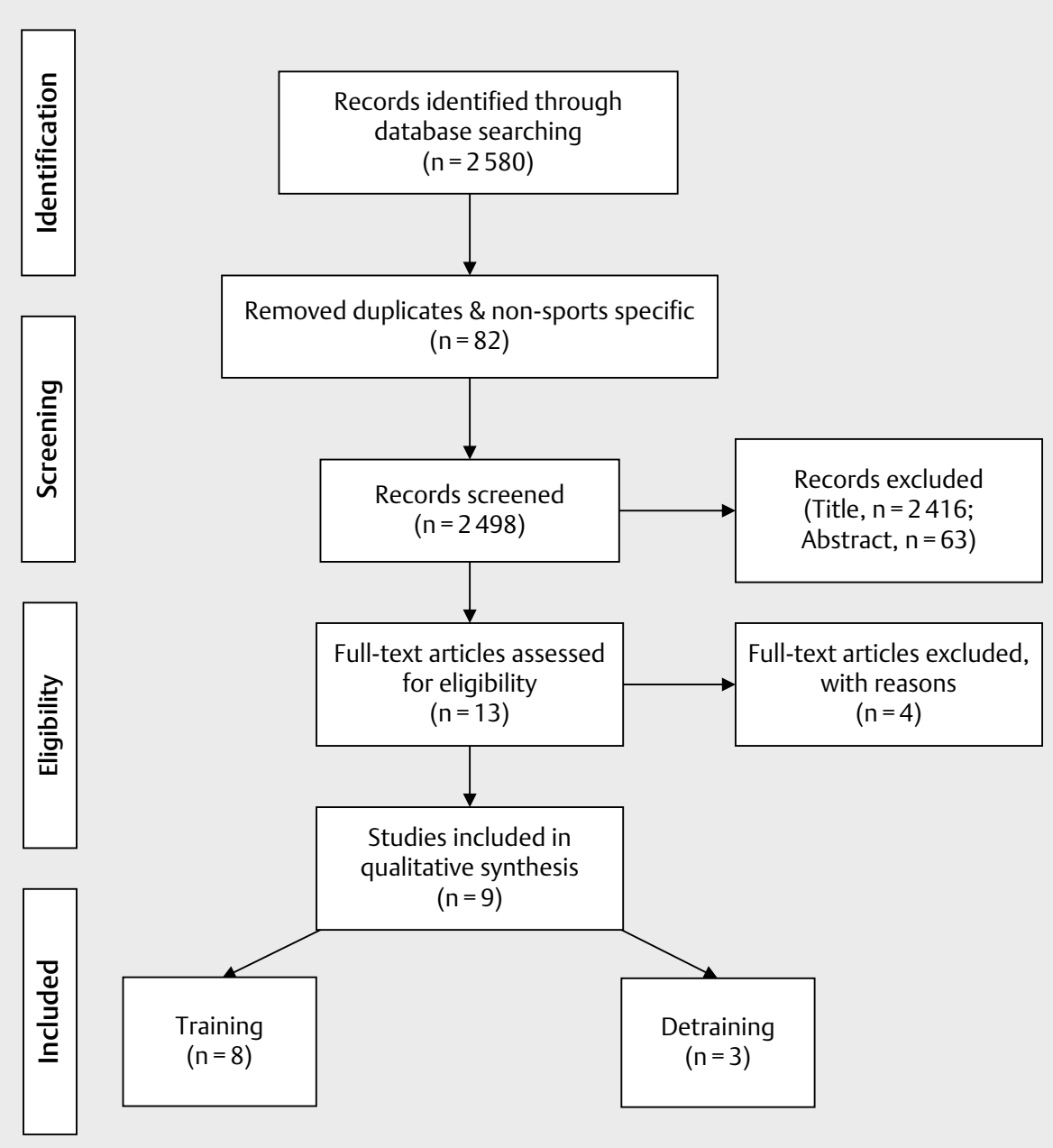

> Fig. 1 PRISMA study flow diagram.

\section{Data analysis}

Assessment of risk of bias

Quality analysis of the identified studies was conducted independently by two researchers using methods recommended by the Cochrane Collaboration [38]. Any conflict was resolved by including an independent researcher. All relevant biases, such as sequence generation, allocation concealment, blinding of participants, personnel and outcomes, incomplete outcome data, selective outcome reporting, and other sources of bias, were checked, and the studies were graded. The following classifications were used: low risk, high risk, or unclear risk (either lack of information or uncertainty regarding the potential for bias). Review Manager software (RevMan, Copenhagen, the Nordic Cochrane Centre) version 5.3.5 was used to create risk-of-bias graphs.

\section{Statistical analysis}

The results of the included studies were used to quantify the percentage of change for each variable during training programs ([post - pre/pre] $\times 100$ ). Moreover, the results of the included studies were recalculated to determine effect sizes (ES) as a measure of the difference between averages in terms of standard deviation units, which provides information about the magnitude of the observed differences. This analysis was calculated using Cohen's d [39], where the post-training values were subtracted from the pre-training values and divided by the combined standard deviation. This method allowed us to determine the magnitude of differences for the studies that provided means and standard deviations. The magnitude of the ESs was considered trivial $(<0.2)$, small $(0.2-0.59)$, moderate $(0.60-1.19)$, large (1.2-1.99) or very large (>2.00) [40].

\section{Results}

- Table 1 presents a summary of the studies that monitored the intensity variations of $\mathrm{CT}$ in young adults (athletes and nonathletes). Of the nine studies included in the current review, most included assessments of strength performance and aerobic capacity $[29,30$, 41-44]. The tests most commonly used to evaluate strength and power-output were the one-repetition maximum (1RM; $67 \%$ of the studies) test [7, 29, 30, 41-43] and the countermovement jump (CM]; $67 \%$ of the studies) [29, 30,41-44], respectively. Aerobic speed and/or oxygen uptake were variables used to evaluate cardiorespiratory fitness in $89 \%$ of the studies $[1,29,30,37,41-44]$. Most 
- Table 1 Characteristics of the studies included in the review.

\begin{tabular}{|c|c|c|c|c|}
\hline Author & Subjects & Age & Duration & Outcomes \\
\hline Esteve-Lanao et al. [37] & 12 runners (male) & 27.0 & 20 weeks & HR; HRpeak; $\mathrm{VO}_{2}$ max; Running performance (10.4 km) \\
\hline Fyfe et al. [41] & 23 physically active (male) & 29.6 & 8 weeks & $\begin{array}{l}1 \mathrm{RM} \text { leg press and bench press; } \mathrm{CM} \text {; } \mathrm{VO}_{2} \text { peak; LT; Body } \\
\text { composition }\end{array}$ \\
\hline Joo, C.H. [1] & $\begin{array}{l}20 \text { semi-professional soccer } \\
\text { players (male) }\end{array}$ & 22.1 & 5 weeks & $\begin{array}{l}\text { Sprint }(30 \mathrm{~m}) \text {; Repeated sprints ( } 34.2 \mathrm{~m}) \text {; Yo-Yo test; Arrowhead } \\
\text { agility test }\end{array}$ \\
\hline Petré et al. [42] & 16 high-level athletes (male) & 27.3 & 6 weeks & $\mathrm{VO}_{2} \max ; \mathrm{VO}_{2}$ max Time limit; [LA-]; MLSS; 1RM; CM]. \\
\hline Silva et al. [7] & 44 physically active (female) & 23.5 & 11 weeks & $\begin{array}{l}\text { Knee extension; Leg press; Bench press; 1RM; Isometric and } \\
\text { isokinetic peak torque }\end{array}$ \\
\hline Sousa et al. [29] & 32 physically active (male) & 20.6 & 12 weeks & Sprint (20 m); CMJ; 1RM; $\mathrm{VO}_{2} \max$ \\
\hline Sousa et al. [30] & 36 physically active (male) & 21.0 & 12 weeks & Sprint (20 m); CMJ; $1 \mathrm{RM} ; \mathrm{VO}_{2} \max$ \\
\hline Varela-Sanz et al. [43] & $\begin{array}{l}35 \text { sport science students } \\
\text { (male and female) }\end{array}$ & $18-27.0$ & 8 weeks & Sprint (10 m; $30 \mathrm{~m}) ; \mathrm{CMJ} ; 1 \mathrm{RM} ; \mathrm{VO}_{2} \max$ \\
\hline Wong et al. [44] & $\begin{array}{l}39 \text { professional soccer players } \\
\text { (male) }\end{array}$ & 24.6 & 8 weeks & $\begin{array}{l}\text { Jump height; Ball-shooting; Sprint }(10 \mathrm{~m} ; 30 \mathrm{~m}) \text {; Yo-yo test; } \\
\text { MAS; HRmax }\end{array}$ \\
\hline
\end{tabular}

of the subjects were males between 20 and 30 years of age. Another important issue was related to the training program duration, which ranged from 5 weeks [1] to 20 weeks [37] of implementation.

The analyzed studies were mainly focused on the exercise intensities during the aerobic component of CT training ( From the 8 selected studies, all experimental interventions induced improvements in the variables assessed, regardless of the intensity used in the resistance training or in the aerobic training. When higher aerobic intensities were combined, the magnitude of changes of maximal oxygen uptake $\left(\mathrm{VO}_{2} \mathrm{max}\right)$ and aerobic power were moderate [41,42]. Moreover, moderate to large neuromuscular adaptations were found when higher resistance training loads were combined with low to moderate aerobic training intensities [29, 30,42].

Focusing on the distribution of exercise intensities during a long-term CT program, it was suggested that an undulating nonlinear periodization model intensities (polarized model), with most of training time spent at light and very hard aerobic intensities, with little at moderated/hard intensities, would be the most effective training intensity distribution for reducing the interference in neuromuscular performance $[37,43]$. Running performance was approximately $2 \%$ greater with polarized training compared to the traditional distribution [37]. Moreover, the upper and lower body maximum strength increased 24 and $47 \%$, respectively, after 8 weeks of polarized training [43].

Among studies on exercise intensities during CT, only 3 (33\%) focused on the issue of detraining. Table 3 presents a summary of the studies that monitored the effects of detraining on physical performance in young adults. Sousa et al. [29] reported that CT loads in resistance training seem not to influence the reversibility of the training effects after a detraining period of 4 weeks. In the same study, the gains obtained from low, moderate and high resistance training loads combined with low-intensity aerobic training decreased between 2 and $15 \%$ after detraining. In accordance with this finding, Joo [1] verified that 2 weeks of detraining after a competitive season resulted in marked decreases in repeated sprints and agility variables of elite soccer players. Moreover, combining different aerobic training intensities with the same resistance training also resulted in performance decrements after 4 weeks of detraining, but smaller performance decrements when lower aerobic training intensity was performed [30].

\section{Risk of bias in the included studies}

The included studies were randomized, but few described the sequence of the randomized generation [1]. Most were not clear regarding the blinding outcome assessment, or this was performed by the main researcher of the study, which reveals high risk of bias [1, 29, 37, 41-44] (• Fig. 2, > 3).

\section{Discussion}

The current review aimed to analyze and compare the scientific evidence regarding aerobic and resistance exercise intensities during $\mathrm{CT}$ and their effect on strength and endurance variables. Moreover, the effect of training intensity during CT on the detraining period was also assessed to better understand the impact on the training cessation. The studies on this topic were relatively recent, with increased interest in the last 2 decades. CT has been studied since the early 1980s; however, only recently researchers have focused on the influence of training intensity during aerobic or resistance training on neuromuscular adaptations. The few studies found have shown improvements in strength and cardiorespiratory performance regardless of the different intensities used in aerobic and/ or resistance training during CT. Nevertheless, it seems to exist a trend toward higher neuromuscular improvements when high resistance training loads were combined with low to moderate aerobic training intensities. The aerobic gains were found to be greater when higher aerobic training intensities were used, regardless of the resistance training intensities.

The increase of interest regarding CT may be due to its potential to simultaneously provide gains in cardiorespiratory fitness and strength $[45,46]$ as well as the short time requirement and the con- 
- Table 2 Effects of intensity during concurrent training in performance.

\begin{tabular}{|c|c|c|c|}
\hline References & Main aim & Intervention & Main findings * \\
\hline $\begin{array}{l}\text { Esteve-Lanao } \\
\text { et al. [37] }\end{array}$ & $\begin{array}{l}\text { Compare different } \\
\text { loads distribution }\end{array}$ & $\begin{array}{l}G 1(n=6): Z 1=80 \% ; Z 2=10 \% ; Z 3=10 \% \\
G 2(n=6): Z 1=65 ; Z 2=25 \% ; Z 3=10 \%\end{array}$ & $\begin{array}{l}{[10.4 \mathrm{~km} \text { time }]^{* *} \mathrm{G} 1:-7 \%, \mathrm{ES}=2.1 ; \mathrm{G} 2:-5 \%} \\
\mathrm{ES}=1.4\end{array}$ \\
\hline $\begin{array}{l}\text { Fyfe et al. } \\
\text { [41] }\end{array}$ & $\begin{array}{l}\text { Effects of different } \\
\text { intensities and types } \\
\text { of } C T\end{array}$ & $\begin{array}{l}\text { G1 }(n=7)=\text { moderate continuous training } 80-100 \% \text { LT + } \\
\sim 65-90 \% 1 \text { RM } \\
\text { G2 }(n=8)=\text { high intensity interval training } 120-150 \% \\
\text { LT }+\sim 65-90 \% 1 R M \\
\text { G3 }(n=8)=\sim 65-90 \% 1 R M\end{array}$ & $\begin{array}{l}{[1 \mathrm{RM} \mathrm{LP}]{ }^{*} * \mathrm{G} 1: 27 \%, \mathrm{ES}=0.8 ; \mathrm{G} 2: 29 \%, \mathrm{ES}=1.2 ;} \\
\mathrm{G} 3: 39 \%, \mathrm{ES}=1.3 \\
{[1 \mathrm{RM} \mathrm{BP}] \mathrm{G} 1: 15 \%, \mathrm{ES}=0.4 ; \mathrm{G} 2: 16 \%, \mathrm{ES}=0.6 ; \mathrm{G} 3:} \\
21 \%, \mathrm{ES}=0.5 ; \\
{[\mathrm{CM} \text { p power] G3: } 13 \%, \mathrm{ES}=0.9} \\
\text { [Peak aerobic power] G2: } 9 \%, \mathrm{ES}=0.3\end{array}$ \\
\hline $\begin{array}{l}\text { Petré et al. } \\
\text { [42] }\end{array}$ & $\begin{array}{l}\text { Effects of different } \\
\text { combinations of AT }\end{array}$ & $\begin{array}{l}\mathrm{G} 1(\mathrm{n}=8)=\geq 80 \% 1 \mathrm{RM}+\mathrm{CT} \text { low volume and HIIT at } \\
\sim 150 \% \mathrm{VO}_{2} \max (4-12 \mathrm{~min}) \\
\mathrm{G} 2(\mathrm{n}=8)=\geq 80 \% 1 \mathrm{RM}+\mathrm{CT} \text { high volume and medium- in- } \\
\text { tensity continuous AT at } 70 \% \mathrm{VO}_{2} \max (40-80 \mathrm{~min})\end{array}$ & $\begin{array}{l}{\left[\mathrm{VO}_{2} \max \right] \mathrm{G} 1: 5 \%, \mathrm{ES}=0.6} \\
{[1 \mathrm{RM} \mathrm{SQ}] \mathrm{G} 1: 14 \%, \mathrm{ES}=0.8 ; \mathrm{G} 2: 12 \%, \mathrm{ES}=0.7}\end{array}$ \\
\hline Silva et al. [7] & $\begin{array}{l}\text { Effects of different } \\
\text { intensities and types } \\
\text { of aerobic exercise }\end{array}$ & $\begin{array}{l}\mathrm{G} 1(\mathrm{n}=10)=\mathrm{RT}+20 \mathrm{~min} \text { continuous running } 95 \% \mathrm{VT}_{2} \\
\mathrm{G} 2(\mathrm{n}=11)=\mathrm{RT}+20 \mathrm{~min} \text { interval running } 1 \mathrm{~min} \text { at } \\
\mathrm{VVO}_{2} \mathrm{max}, 1 \mathrm{~min} \text { of active recovery at } 50 \% \mathrm{VVO}_{2} \mathrm{max} ; \\
\mathrm{G} 3(\mathrm{n}=11)=\mathrm{RT}+\text { continuous cycle ergometer } 95 \% \mathrm{VT}_{2} \\
\mathrm{G} 4(\mathrm{n}=12)=\mathrm{RT}\end{array}$ & $\begin{array}{l}{[1 \mathrm{RM} \text { LP] G1: } 41 \%, \mathrm{ES}=2.3 ; \mathrm{G} 2: 47 \%, \mathrm{ES}=2.2 ; \mathrm{G} 3:} \\
39 \%, \mathrm{ES}=1.8 ; \mathrm{G} 4: 53 \%, \mathrm{ES}=2.0 \\
{[1 \mathrm{RM} \mathrm{BP}] \mathrm{G} 1: 19 \%, \mathrm{ES}=1.1 ; \mathrm{G} 2: 18 \%, \mathrm{ES}=1.0 ; \mathrm{G} 3:} \\
17 \%, \mathrm{ES}=1.4 ; \mathrm{G} 4: 21 \%, \mathrm{ES}=0.9\end{array}$ \\
\hline $\begin{array}{l}\text { Sousa et al. } \\
\text { [29] }\end{array}$ & $\begin{array}{l}\text { Compare different } \\
\text { external loads of RT } \\
\text { during } C T\end{array}$ & $\begin{array}{l}\text { G1 }(n=9)=40-55 \% 1 R M+20 \min (75 \% \text { MAS) } \\
\text { G2 }(n=9)=55-70 \% 1 R M+20 \min (75 \% \text { MAS) } \\
\text { G3 }(n=8)=70-85 \% 1 R M+20 \min (75 \% \text { MAS) } \\
\text { CG }(n=6)=\text { No training }\end{array}$ & 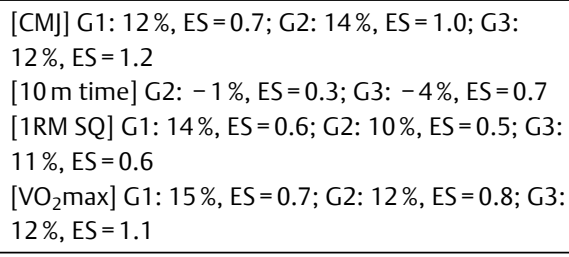 \\
\hline $\begin{array}{l}\text { Sousa et al. } \\
\text { [30] }\end{array}$ & $\begin{array}{l}\text { Compare different } \\
\text { aerobic intensities } \\
\text { during CT }\end{array}$ & $\begin{array}{l}G 1(n=10)=70-85 \% 1 R M+16-20 \mathrm{~min} \text { at } 80 \% \text { MAS } \\
\text { G2 }(n=10)=70-85 \% 1 R M+16-20 \mathrm{~min} \text { at } 90 \% \text { MAS } \\
\text { G3 }(n=10)=70-85 \% 1 R M+16-20 \mathrm{~min} \text { at } 100 \% \text { MAS } \\
\text { CG }(n=6)=\text { No training }\end{array}$ & 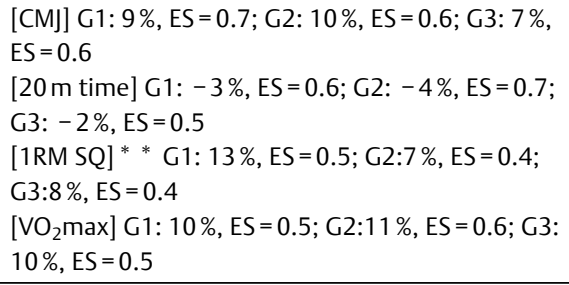 \\
\hline $\begin{array}{l}\text { Varela-Sanz } \\
\text { et al. [43] }\end{array}$ & $\begin{array}{l}\text { Influence of intensity } \\
\text { distribution }\end{array}$ & $\begin{array}{l}\text { G1 }(n=12)=\text { Traditional-based training: } 24-37 \text { min of } \\
\text { running at } 65-75 \% \text { MAS }+3-5 \times 10-12 \text { RM; } \\
\text { G2 }(n=12)=\text { Polarized training: } 35-65 \text { min of brisk walking } \\
\text { at } 30-40 \% \text { MAS and } 120 \% \text { MAS }(1 \text { per week })+3-5 \times 5 \text { RM } \\
\text { or } 2-4 \times 15 \text { RM. } \\
\text { CG }(n=11)=\text { No CT training }\end{array}$ & $\begin{array}{l}\text { [CM]] G1: }-7 \%, E S=0.4 ; C G:-8 \%, E S=0.7 \\
\text { [1RM SQ] G1:40\%, ES=1.4; G2:47\%, ES=1.4 } \\
\text { [1RM BP] G1: } 17 \%, E S=0.7 ; G 2: 24 \%, E S=0.8 \\
\text { [MAS] G1:4\%, ES=0.4; G2:4\%, ES=0.3 }\end{array}$ \\
\hline $\begin{array}{l}\text { Wong et al. } \\
\text { [44] }\end{array}$ & $\begin{array}{l}\text { Effect of high-inten- } \\
\text { sity CT }\end{array}$ & $\begin{array}{l}\text { CG }(n=19) \text { : Soccer training } \\
\text { G1 }(n=20) \text { : Soccer training + high intensity CT (RT } 4 \times 6 \text { RM; } \\
\text { AT } 120 \% \text { MAS). }\end{array}$ & $\begin{array}{l}[\mathrm{CM}]]^{*} \mathrm{*} 1: 4 \%, \mathrm{ES}=2.0 \\
{\left[30 \mathrm{~m} \text { time }{ }^{* *} \mathrm{G} 1:-3 \%, \mathrm{ES}=4.0\right.} \\
{[\mathrm{YYIRT}] \mathrm{G} 1: 20 \%, \mathrm{ES}=3.5} \\
{[\mathrm{MAS}] \mathrm{G} 1: 3 \%, \mathrm{ES}=2.5}\end{array}$ \\
\hline \multicolumn{4}{|c|}{ 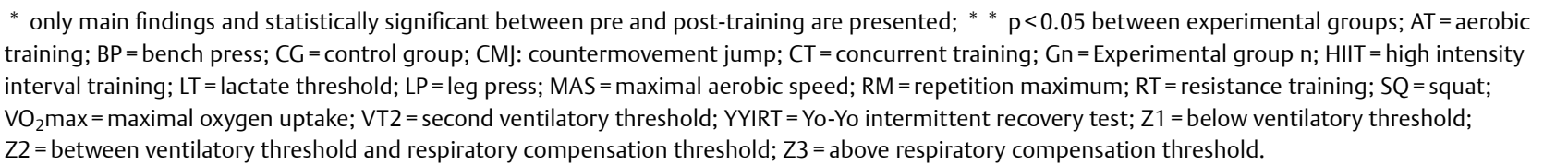 } \\
\hline
\end{tabular}

venience of this training program for several sports disciplines [47]. In several sports, CT is a usual method of training, as it combines the specific motions of sports, such as swimming or running, with resistance training to obtain gains in several actions/tasks crucial for increase sport performance [48-51]. Our search revealed that among the studies on CT intensity, only a few reported data on professional athletes $[37,42,44]$. Non-athletes are also an important cohort, and they were studied in several reports $[1,7,29,30,43]$. Therefore, one of the main problems detected by the present review was that further studies must be conducted with competitive individuals.
From the selected studies, only Sousa et al. [29] focused on the intensities of resistance training in CT. Sousa and colleagues [29] suggested resistance training programs with low, moderate and high external loads combined with low-intensity aerobic training to produce gains in strength and aerobic capacities. Moreover, they suggested that loads higher than 55\% 1RM of resistance training combined with low-intensity aerobic training were efficient in improving rapid voluntary muscle contractions, such as short runs and CMJ. However, few is known regarding the effects of concurrent resistance training with higher loads, combined with high intensities of aerobic training on physical performance of young 
- Table 3 Effects of concurrent training intensities after detraining.

\begin{tabular}{|c|c|c|c|}
\hline References & Main aim & Intervention & Main findings \\
\hline Joo [1] & $\begin{array}{l}\text { Effects of HIT with } \\
\text { reduced volume and } \\
\text { training cessation }\end{array}$ & $\begin{array}{l}\text { G1 }=\text { DT combined with high-intensity AT } \\
(3 \times 12 \text { min at } 80-90 \% \text { of HRmax }) \\
\text { G2 = DT with no physical activity. } \\
\text { DT for } 2 \text { weeks after a soccer season }\end{array}$ & $\begin{array}{l}\text { [Agility] G1: } 2 \%, E S=0.7 ; G 2: 1 \%, E S=0.5 \\
{[30 \text { m time] G1: } 2 \% . E S=0.6 ; G 2: 2 \%, E S=0.7} \\
{[\text { Yo-Yo] G2: }-20 \% \#} \\
\text { [Repeated sprints time] G2: } 5 \% \#\end{array}$ \\
\hline Sousa et al. [29] & $\begin{array}{l}\text { Compare different } \\
\text { external loads of RT } \\
\text { during CT followed by } \\
\text { 4-weeks DT }\end{array}$ & $\begin{array}{l}\text { DT of } 4 \text { weeks after } C T \text { for } 8 \text { weeks } \\
\text { G1 }=40-55 \% 1 \text { RM }+20 \min (75 \% \mathrm{MAS}) \\
\mathrm{C} 2=55-70 \% 1 \mathrm{RM}+20 \mathrm{~min}(75 \% \mathrm{MAS}) \\
\mathrm{G} 3=70-85 \% 1 \mathrm{RM}+20 \mathrm{~min}(75 \% \mathrm{MAS})\end{array}$ & $\begin{array}{l}{[20 \mathrm{~m} \text { time] G1: } 2 \%, E S=0.4 ; \mathrm{G} 2: 4 \%, \mathrm{ES}=1.0 ; \mathrm{G} 3:} \\
3 \%, \mathrm{ES}=0.8 \\
{[1 \mathrm{RM} \text { SQ] G1: }-7 \%, \mathrm{ES}=0.4} \\
{\left[\mathrm{VO}_{2} \mathrm{max}\right] \mathrm{G}:-15 \%, \mathrm{ES}=1.1 ; \mathrm{G} 3:-9 \%, \mathrm{ES}=0.9}\end{array}$ \\
\hline Sousa et al. [30] & $\begin{array}{l}\text { Compare different } \\
\text { aerobic intensities during } \\
\text { CT followed by 4-weeks } \\
\text { DT }\end{array}$ & $\begin{array}{l}\text { DT of } 4 \text { weeks after CT for } 8 \text { weeks } \\
\text { G1 }(n=10)=70-85 \% 1 \text { RM }+16-20 \mathrm{~min} \text { at } 80 \% \text { MAS } \\
\text { G2 }(n=10)=70-85 \% 1 \text { RM }+16-20 \mathrm{~min} \text { at } 90 \% \text { MAS } \\
\text { G3 }(n=10)=70-85 \% 1 R M+16-20 \mathrm{~min} \text { at } 100 \% \\
\text { MAS }\end{array}$ & $\begin{array}{l}\text { [CMJ] G1: }-3 \%, E S=0.3 ; G 2:-5 \%, E S=0.3 \\
{[20 m \text { time] G2: } 2 \%, E S=0.5} \\
\text { [1RM SQ] G1: }-8 \%, E S=0.4 ; G 2:-10 \%, E S=0.4 ; \\
\text { G3: }-10 \%, E S=0.5 \\
{\left[\mathrm{VO}_{2} \text { max] G2: }-5 \%, E S=0.3 ; G 3:-7 \%, E S=0.4\right.}\end{array}$ \\
\hline
\end{tabular}

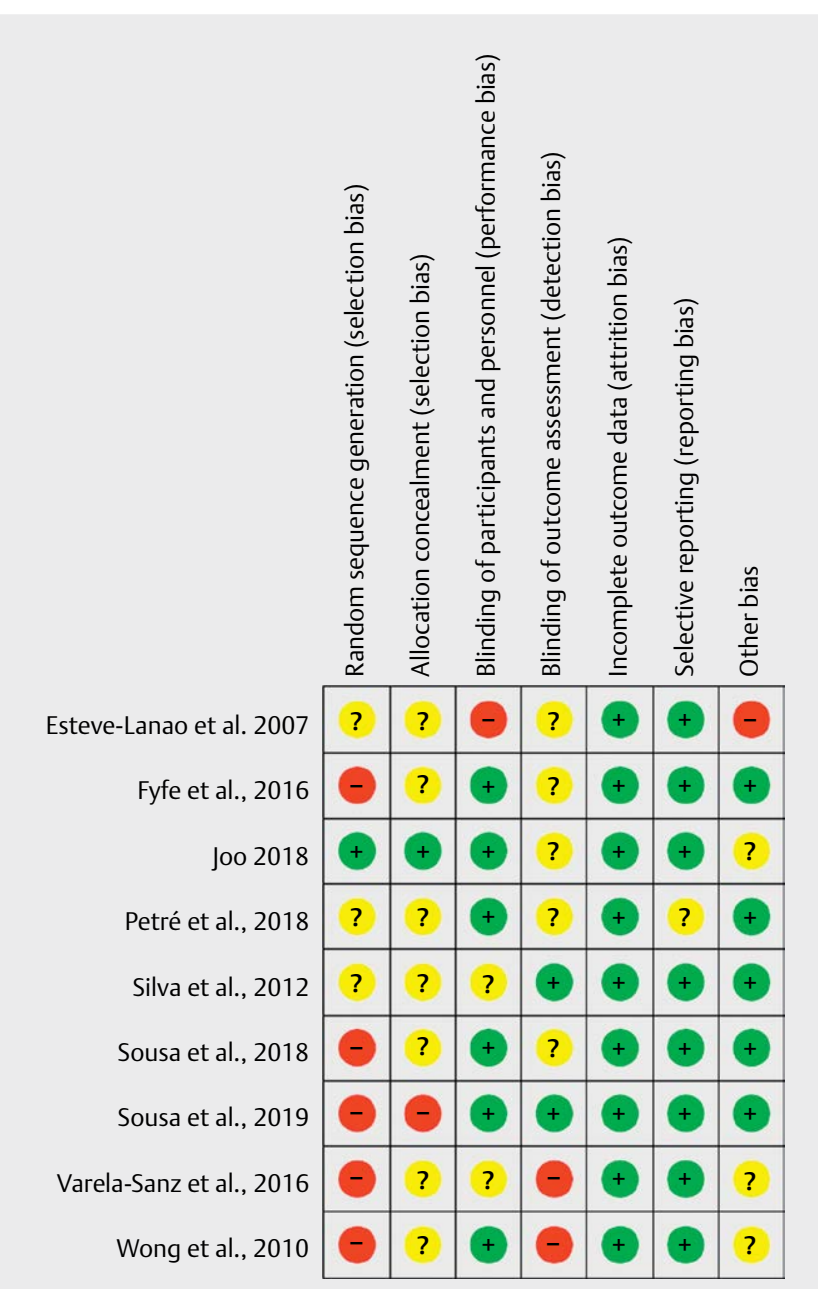

- Fig. 2 Judgements about each risk of bias item for each included study.

adults. In this sense, it has been described that higher intensities of aerobic training can cause greater metabolic perturbation in type II muscle fibers and potentially compromise anabolic respons- es from strength training $[52,53]$. Thus, these findings highlight the importance of further knowledge on the intensities of resistance training during CT so that coaches could minimize the interference phenomenon and efficiently improve performance.

The study of the intensity during CT was mostly restricted to the aerobic component. For instance, Silva et al. [7] reported that different intensities of aerobic training, combined with the same resistance training, twice a week for eleven weeks, does not seem to differently affect the strength development. Thus, it would be suggested that different intensities of aerobic training enhance athletes' performances in similar magnitudes. Concordantly, Fyfe et al. [41] evidenced that eight weeks of high-intensity or moderate-intensity of cycling for 15-33 min combined with the same resistance training induced improvements in maximal strength and neuromuscular performance. However, when compared with resistance training alone, both aerobic intensities similarly attenuated improvements in maximal lower-body strength (1RM and CMJ). Thus, we should highlight the similarity of the gains between the different training intensities, but we should not disregard the possible interference effect on strength gains by the moderate and high intensities used [22].

It was previously suggested that the high intensity aerobic exercise could impair acute molecular interference and attenuate the anabolic response $[22,54]$. The higher aerobic intensities may increase glycogen depletion and intensify residual fatigue, possibly compromising muscle regeneration and training adaptations [55]. Studies independently examining the effect of aerobic exercise intensity on concurrent training are scarce. It seems difficult for the researchers to investigate different aerobic intensities during CT without changing the volumes or methods of training. This is easily explained by the high intensities used, which require some rest or even reduction of the exercise duration, resulting in changes of training methods. As evidenced by Fyfe et al. [41], two different methods of aerobic training are usually compared (continuous vs. interval) and this could affect the conclusions obtained. Recently, Petré et al. [42] compared different aerobic training intensities (low volume of high intensity interval training vs. high volume of moderate continuous training) combined with the same resistance training (loads higher than $80 \% 1 \mathrm{RM}$ ) in former competitive ath- 


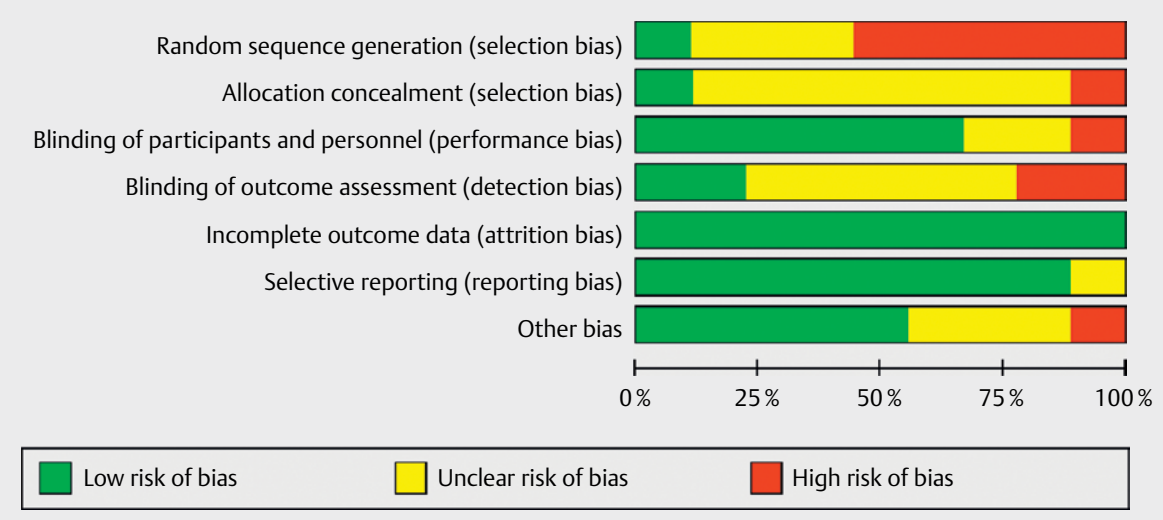

- Fig. 3 Risk of bias item presented as percentages across all included studies.

letes. These authors found that strength improved with high and low intensities of aerobic training. However, $\mathrm{VO}_{2}$ max gains were only found when resistance training was combined with low volume of high intensity interval training. This suggested that higher aerobic intensities should be used during CT for greater aerobic performances [30,42].

Recently Sousa et al. [30] aimed to verify the effects of low, moderate or high intensities of running exercise combined with the same resistance training on strength and aerobic performances. Strength performance (1RM) was significantly higher in the lowintensity aerobic training than moderate and high intensities and there were moderate positive effects in sprint and $\mathrm{CM}$ J performances. Moreover, these authors found that when lower aerobic intensities were implemented during CT, smaller performance decrements were shown after detraining period. Conversely, recent reviews $[27,34]$ on CT suggested that high intensity interval training can be prescribed alongside resistance training without negatively impacting changes in muscle mass. Despite it seemed contradictory recommendations, all seemed to agree that an adequate rest between aerobic and resistance training sessions should be provided for these gains to occur. Coffey and Hawley [21] warned for the fact that recommending divergent exercise modes on different days to avoid interference effect of concurrent training is simplistic and not representative of the real training and competition context. Therefore, when training in the same training session, it is recommended to choose lower aerobic intensities for increased strength gains [30].

Research on CT issues has also focused on the distribution of training intensities throughout the season $[37,43]$. In this regard, Esteve-Lanao et al. [37] sought to understand how the day-to-day aerobic training intensity should be distributed and combined with the same resistance training program in order to obtain the greater improvements in physical performance. The training intensity during endurance training was typically divided into different arbitrary intensity zones ( $Z 1$ = below ventilatory threshold; $Z 2$ = between ventilatory threshold and respiratory compensation threshold; Z3 = above respiratory compensation threshold), and the authors aimed to verify the effects of a traditional training program emphasizing moderately high-intensity aerobic training or those of a new trend of polarized training emphasizing the low-intensity zone. After 21 weeks of training program, the runners who com- bined resistance training with polarized aerobic training emphasizing low-intensity training zones resulted in greater $10.4 \mathrm{~km}$ performance enhancements than the others. Interestingly, another recent study [43] suggested that 8 weeks of traditional training-based regimens (i. e., moderate volume and intensity of $\mathrm{CT}$ ) produced similar improvements in neuromuscular and cardiorespiratory fitness as polarized training. Discrepancies between results of both studies $[37,43]$ could be due to differences in training duration (8 vs. 21 weeks) and sample characteristic (sports science students vs. competitive sub-elite athletes). Therefore, training intensity distribution seems to be irrelevant for training programs lasting a few weeks for non-athletes, but polarized training is suggested as the most effective training intensity distribution for improving competitive performance [37].

Regarding the detraining period, only three studies analyzed the effects of CT intensities during training cessation [1, 29, 30]. These studies revealed that the training-induced gains may be compromised with short-term detraining period (2-4 weeks), leading to a return to baseline values $[1,29]$. Sousa et al. [29, 30] demonstrated that a 4-week period of training cessation after CT with different resistance or aerobic training loads compromised traininginduced gains in young men. In the study by Joo [1], only 2 weeks of detraining after a competitive season markedly decreased performance. Therefore, despite scarce evidence, it seemed that regardless of the intensities of the previous endurance and resistance training during $\mathrm{CT}$, only $2-4$ weeks of training cessation can cause a significant and marked loss of performance. Some possible causes for this performance impairment could be the change in skeletal muscle morphology, a reduction in mean fast twitch fiber crosssectional area, a reduction of oxidative enzyme activities, in glycogen synthase activity and in mitochondrial ATP production [32]. However, when different aerobic training intensities (80 vs. 90 vs. $100 \%$ of maximal aerobic speed) were combined with the same resistance training, the lower intensities showed smaller decrements during detraining, especially in $\mathrm{VO}_{2}$ max [30].

The scientific evidence and knowledge that is provided by the current review should be helpful for coaches and professionals to improve the training program design and consequently enhance performance. Moreover, it was clear that this issue is still unknown, and that further research is required. It is important to understand 
the effect of different resistance training intensities and/or different aerobic training intensities and then investigate methods of combining these exercise modalities. Moreover, more research on competitive athletes should be conducted and longitudinal studies with longer training periods should be developed to analyze the interference of CT at different intensities and how performance changes over time.

To the best of our knowledge, no detailed systematic review has comprehensively examined the literature regarding the effects of the intensities used in a CT training program, specifically in the aerobic or/and resistance training component. However, we found some limitations in the comparison of the results presented by the different investigations, and recommendations concerning optimal intensities to use during CT were designed based on the present data. It is worth noting that there were differences in the subject's characteristics (athletes and non-athletes) and even in the training programs (frequency, intensities, type) between the included studies that conditioned the analysis. Furthermore, only few studies were found on this issue and some methodological quality flaws compromised general conclusions. Moreover, longer interventions should be studied for a better understanding of this subject.

In brief, despite the lack of longitudinal studies on different CT intensities and performance, it seems evident that $\mathrm{CT}$ with different intensities positively influences the performance of young adults. Furthermore, short-term training cessation (2-4 weeks) compromises the training-induced gains. The few studies revealed greater strength and neuromuscular performance gains when the CT program combined high-intensity resistance training with lowintensity aerobic training (e. g., $70-85 \% 1 \mathrm{RM}$ and $80 \%$ of maximal aerobic speed), and an interference effect seemed to exist for higher aerobic exercise intensities. Higher aerobic exercise intensities (e. g., interval training at $150 \% \mathrm{VO}_{2}$ max or higher than $90 \%$ of maximal aerobic speed) should be used to improve cardiorespiratory fitness, but improvements in strength could be compromised. Regarding the intensity distribution during the aerobic regimen, the polarized model may be better at reducing interference in neuromuscular performance. Nevertheless, we should be cautious and consider these findings to be tendencies, while being aware that further research is needed on this matter. The information shown in this review could provide useful tools for coaches to develop efficient training programs. Athletes and coaches should design their $\mathrm{CT}$ program according to their main goal of increasing aerobic or strength capacity.

\section{Acknowledgements}

This project was supported by national funding through the Portuguese Foundation for Science and Technology, I.P., under project UID/DTP/04045/2019 and the European Fund for Regional Development (FEDER) allocated by European Union through the COMPETE 2020 Programme (POCI-01-0145-FEDER-006969) - competitiveness and internationalization (POCI). Mikel Izquierdo is funded in part by a research grant PI17/01814 of the Ministerio de Economía, Industria y Competitividad (ISCIII, FEDER).

\section{Conflict of Interest}

Authors declare that they have no conflict of interest.

\section{References}

[1] Joo $\mathrm{CH}$. The effects of a short term detraining and retraining on physical fitness in elite soccer players. PLoS One 2018; 13: e0196212

[2] Schumann M, Yli-Peltola K, Abbiss CR, Häkkinen K. Cardiorespiratory adaptations during concurrent aerobic and strength training in men and women. PLoS One 2015; 10: e0139279

[3] Davis W], Wood DT, Andrews RG, Elkind LM, Davis WB. Concurrent training enhances athletes' cardiovascular and cardiorespiratory measures. J Strength Cond Res 2008; 22: 1503-1514

[4] Davis WJ, Wood DT, Andrews RG, Elkind LM, Davis WB. Concurrent training enhances athletes' strength, muscle endurance, and other measures. J Strength Cond Res 2008; 22: 1487-1502

[5] Garcia-Pallares ], Izquierdo M. Strategies to optimize concurrent training of strength and aerobic fitness for rowing and canoeing. Sports Med 2011; 41: 329-343

[6] Izquierdo-Gabarren M, Gonzalez De Txabarri Exposito R, Garcia-pallares J, Sánchez-medina L, De Villarreal ES, Izquierdo M. Concurrent endurance and strength training not to failure optimizes performance gains. Med Sci Sports Exerc 2010; 42: 1191-1199

[7] Silva RF, Cadore EL, Kothe G, Guedes M, Alberton CL, Pinto SS, Pinto RS, Trindade G, Kruel LF. Concurrent training with different aerobic exercises. Int J Sports Med 2012; 33: 627-634

[8] Alves AR, Marta CC, Neiva HP, Izquierdo M, Marques MC. Concurrent training in prepubescent children: The effects of 8 weeks of strength and aerobic training on explosive strength and $\mathrm{VO}_{2}$ max. J Strength Cond Res 2016; 30: 2019-2032

[9] Cadore EL, Pinto RS, Pinto SS, Alberton CL, Correa CS, Tartaruga MP, Silva EM, Almeida AP, Trindade GT, Kruel LF. Effects of strength, endurance, and concurrent training on aerobic power and dynamic neuromuscular economy in elderly men. J Strength Cond Res 2011; 25: 758-766

[10] Docherty D, Sporer B. A proposed model for examining the interference phenomenon between concurrent aerobic and strength training. Sports Med 2000; 30: 385-394

[11] Gravelle BL, Blessing DL. Physiological adaptation in women concurrently training for strength and endurance. J Strength Cond Res 2000; 14: 5-13

[12] Hakkinen K, Alen M, Kraemer WJ, Gorostiaga E, Izquierdo M, Rusko H, Mikkola J, Hakkinen A, Valkeinen H, Kaarakainen E, Romu S, Erola V, Ahtiainen J, Paavolainen L. Neuromuscular adaptations during concurrent strength and endurance training versus strength training. Eur J Appl Physiol 2003; 89: 42-52

[13] Leveritt M, Abernethy PJ, Barry BK, Logan PA. Concurrent strength and endurance training: A review. Sports Med 1999; 28: 413-427

[14] McCarthy JP, Pozniak MA, Agre JC. Neuromuscular adaptations to concurrent strength and endurance training. Med Sci Sports Exerc 2002; 34: 511-519

[15] Sale DG, MacDougall JD, Jacobs I, Garner S. Interaction between concurrent strength and endurance training. J Appl Physiol (1985) 1990; 68: $260-270$

[16] Bishop D, Jenkins DG. The effects of strength training on endurance performance and muscle characteristics. Med Sci Sports Exerc 1999; 31: 886-891

[17] Chtara M, Chamari K, Chaouachi M, Chaouachi A, Koubaa D, Feki Y, Millet G, Amri M. Effects of intra-session concurrent endurance and strength training sequence on aerobic performance and capacity. $\mathrm{Br}$ J Sports Med 2005; 39: 555-560 
[18] McCarthy JP, Agre JC, Graf BK, Pozniak MA, Vailas AC. Compatibility of adaptive responses with combining strength and endurance training. Med Sci Sports Exerc 1995; 27: 429-436

[19] Millet GP, Jaouen B, Borrani F, Candau R. Effects of concurrent endurance and strength training on running economy and $\mathrm{VO}_{2}$ kinetics. Med Sci Sports Exerc 2002; 34: 1351-1359

[20] Paavolaiınen L, Hakkinen K, Hamalainen I, Nummela A, Rusko H. Explosive-strength training improves $5-\mathrm{km}$ running time by improving running economy and muscle power. J Appl Physiol (1985) 1999; 86: 1527-1533

[21] Coffey VG, Hawley JA. Concurrent exercise training: Do opposites distract? J Physiol 2017; 595: 2883-2896

[22] Fyfe J], Bishop DJ, Stepto NK. Interference between concurrent resistance and endurance exercise: Molecular bases and the role of individual training variables. Sports Med 2014; 44: 743-762

[23] Schoenfeld B]. The mechanisms of muscle hypertrophy and their application to resistance training. J Strength Cond Res 2010; 24: 2857-2872

[24] Hennessy L, Watson A. The interference effects of training for strength and endurance simultaneously. J Strength Cond Res 1994; 8: 12-19

[25] Jones T, Howatson G, Russell M, French DN. Performance and neuromuscular adaptations following differing ratios of concurrent strength and endurance training. J Strength Cond Res 2013; 27: 3342-3351

[26] Karavirta L, Hakkinen A, Sillanpaa E, García-López D, Kauhanen A, Haapasaari A, Alen M, Pakarinen A, Kraemer W], Izquierdo M, Gorostiaga E, Hakkinen K. Effects of combined endurance and strength training on muscle strength, power, and hypertrophy in 40-67-yearold men. Scand J Med Sci Sports 2011; 21: 402-411

[27] Methenitis S. A brief review on concurrent training: From laboratory to the field. Sports (Basel) 2018; 6: E127

[28] Wilson JM, Marin PJ, Rhea MR, Wilson SMC, Loenneke JP, Anderson JC. Concurrent training: A meta-analysis examining interference of aerobic and resistance exercises. J Strength Cond Res 2012; 26 : 2293-2307

[29] Sousa AC, Marinho DA, Gil MH, Izquierdo M, Rodríguez-Rosell D, Neiva HP, Marques MC. Concurrent training followed by detraining: Does the resistance training intensity matter? | Strength Cond Res 2018; 32: 632-642

[30] Sousa AC, Neiva HP, Gil MH, Izquierdo M, Rodríguez-Rosell D, Marques MC, Marinho DA. Concurrent training and detraining: The influence of different aerobic intensities. J Strength Cond Res 2019, doi:10.1519/ JSC.0000000000002874

[31] Faigenbaum AD, Kraemer W], Blimkie C], Jeffreys I, Micheli L], Nitka M, Rowland TW. Youth resistance training: Updated position statement paper from the national strength and conditioning association. J Strength Cond Res 2009; 23: S60-S79

[32] Mujika I, Padilla S. Detraining: loss of training-induced physiological and performance adaptations. Part I: Short term insufficient training stimulus. Sports Med 2000; 30: 79-87

[33] Issurin VB. New horizons for the methodology and physiology of training periodization. Sports Med 2010; 40: 189-206

[34] Sabag A, Najafi A, Michael S, Esgin T, Halaki M, Hackett D. The compatibility of concurrent high intensity interval training and resistance training for muscular strength and hypertrophy: A systematic review and meta-analysis. J Sports Sci 2018; 36: 2472-2483

[35] Moher D, Shamseer L, Clarke M, Ghersi D, Liberati A, Petticrew M, Shekelle P, Stewart LA.PRISMA-P Group. Preferred reporting items for systematic review and meta-analysis protocols (PRISMA-P) 2015 statement. Syst Rev 2015; 4: 1
[36] Harriss DJ, Macsween A, Atkinson G. Standards for ethics in sport and exercise science research: 2018 Update. Int J Sports Med 2017; 38 1126-1131

[37] Esteve-Lanao J, Foster C, Seiler S, Lucia A. Impact of training intensity distribution on performance in endurance athletes. J Strength Cond Res 2007; 21: 943-949

[38] Higgins JP, Green S. Cochrane Handbook for Systematic Reviews of Interventions Version 5.1.0 [updated March 2011].The Cochrane Collaboration; Eds. 2011. Available from www.handbook.cochrane.org (accessed on 28th November 2018)

[39] Cohen J. Statistical Power Analysis for the Behavioural Sciences. Hillsdale. N]: Lawrence Erlbaum Associates Publishers; 1988: 531

[40] Hopkins W, Marshall S, Batterham A, Hanin J. Progressive statistics for studies in sports medicine and exercise science. Med Sci Sports Exerc 2009; 41: 3-13

[41] Fyfe J], Bartlett JD, Hanson ED, Stepto NK, Bishop DJ. Endurance training intensity does not mediate interference to maximal lower-body strength gain during shot-term concurrent training. Front Physiol 2016; 7: 487

[42] Petré $\mathrm{H}$, Lofving P, Psilander N. The effect of two different concurrent training programs on strength and power gains in highly-trained individuals. J Sports Sci Med 2018; 17: 167-173

[43] Varela-Sanz A, Tuimil JL, Abreu L, Boullosa DA. Does concurrent training intensity distribution matter? J Strength Cond Res 2016; 31: 181-195

[44] Wong P, Chaouachi A. Effect of preseason concurrent muscular strength and high-intensity interval training in professional soccer players. J Strength Cond Res 2010; 24: 653-660

[45] Beni MA. Determine the effect of concurrent strength-endurance training on aerobic power and body composition in Non-athletic male students. Ann Biol Res 2012; 3: 395-401

[46] Kang J, Ratamess N. Which comes first? Resistance before aerobic exercise or vice versa? ACSMs Health Fit J 2014; 18: 9-14

[47] Alves JV, Saavedra F, Simão R, Novaes J, Rhea MR, Green D, Reis VM. Does aerobic and strength exercise sequence in the same session affect the oxygen uptake during and post-exercise? J Strength Cond Res 2012; 26: 1872-1878

[48] Balsalobre-Fernández C, Santos-Concejero J, Grivas GV. Effects of strength training on running economy in highly trained runners: $A$ systematic review with meta-analysis of controlled trials. J Strength Cond Res 2016; 30: 2361-2368

[49] Botonis PG, Toubekis AG, Platanou TI. Concurrent strength and interval endurance training in elite water polo players. J Strength Cond Res 2016; 30: 126-133

[50] Crowley E, Harrison A], Lyons M. The impact of resistance training on swimming performance: A systematic review. Sports Med 2017; 47: 2285-2307

[51] Rønnestad BR, Mujika I. Optimizing strength training for running and cycling endurance performance: A review. Scand J Med Sci Sports 2014; 24: 603-612

[52] Gollnick PD, Piehl K, Saltin B. Selective glycogen depletion pattern in human muscle fibres after exercise of varying intensity and at varying pedalling rates. J Physiol 1974; 241: 45-57

[53] Thomson JA, Green HJ, Houston ME. Muscle glycogen depletion patterns in fast twitch fibre subgroups of man during submaximal and supramaximal exercise. Pflugers Arch 1979; 379: 105-108

[54] Coffey VG, Jemiolo B, Edge J, Garnham AP, Trappe SW, Hawley JA. Effect of consecutive repeated sprint and resistance exercise bouts on acute adaptive responses in human skeletal muscle. Am J Physiol Regul Integr Comp Physiol 2009; 297: R1441-R1451

[55] Egan B, Zierath JR. Exercise metabolism and the molecular regulation of skeletal muscle adaptation. Cell Metab 2013; 17: 162-184 